\title{
Penerapan Optimasi Media Sosial Twitter Pada Website Penjualan Online Untuk Meningkatkan Jumlah Pengunjung
}

\author{
Yulinda Nurhafina1, Wahyudi Agustiono ${ }^{2 *}$, Yoga Dwitya Pramudita ${ }^{3}$ \\ 1,2,3 Jurusan Teknik Informatika, Fakultas Teknik, Universitas Trunojoyo Madura, Bangkalan, Jawa Timur \\ Email: ${ }^{1}$ yulindanurhafina074@gmail.com, ${ }^{2 *}$ wahyudi.agustiono@trunojoyo.ac.id, ${ }^{3}$ yoga@ trunojoyo.ac.id
}

(Naskah masuk: 22 Feb 2020, direvisi: 28 Mar 2020, diterima: 1 Apr 2020)

\begin{abstract}
Abstrak
Saat ini banyak perusahaan termasuk pengusaha batik di Madura telah memanfaatkan internet sebagai media pemasaran agar dapat menjangkau lebih banyak pelanggan dan area yang lebih luas. Hal ini karena internet memiliki kemampuan dalam diseminasi informasi kepada penggunanya secara cepat, murah, dan interaktif tanpa dibatasi oleh jarak dan waktu. Namun demikian, para pengusaha umumnya hanya mengandalkan website di dalam melakukan internet marketing ini. Akibatnya tidak jarang meskipun sudah memiliki website, para pengusaha batik di Madura sering kesulitan mendapatkan calon pembeli yang pada akhirnya akan menurunkan pendapatan. Penelitian terdahulu menyebutkan bahwa salah satu cara yang dapat digunakan untuk meningkatkan jumlah pengunjung dan popularitas website yaitu dengan menerapkan teknik Social Media Optimization (SMO). Oleh karena itu penelitian ini bertujuan untuk menerapkan metode SMO dengan memanfaatkan media sosial Twitter pada website penjualan online batik Madura untuk meningkatkan trafik pengunjung. Pada penelitian ini, SMO diterapkan, diuji, dan diukur nilai signifikansinya untuk mengetahui pengaruh trafik pengunjung terhadap website penjualan online batik Madura. Dari hasil pengujian yang telah diterapkan, pengunjung mengalami peningkatan yang signifikan di bulan kedua. Dilihat berdasarkan uji nilai t menggunakan paired t-test dimana korelasi antara sebelum dan sesudah dioptimasi sebesar $2 \%$, dan t hitung 3,548 > t tabel 1,697 dengan nilai signifikansi 0,001 < alfa 0,05, yang berarti H0 ditolak dan H1 diterima atau hipotesis diterima. Hal ini menunjukkan bahwa metode SMO menggunakan Twitter dapat mempengaruhi peningkatan pengunjung meskipun dengan hasil yang ringkas.
\end{abstract}

Kata Kunci: Social Media Optimization, Twitter, Website, Batik Madura.

\section{Application of Twitter Social Media Optimization on Online Webstore to Improve Visitors' Traffic}

\begin{abstract}
In recent years, companies, including Small Medium Enterprises (SMEs) of Batik in Madura Island have widely utilized the internet as a medium for marketing to reach more customers within a wide area. This is because the internet has offered the ability to disseminate information to the users faster, cheaper, and more interactive than any other media. Apparently, most of the SMEs only rely on their websites when it comes to promote or market their products. As a result, they often have difficulties in getting potential buyers, even though they already set up their websites and this could reduce their revenue. Prior studies suggested that one way to increase the websites' traffic and popularity is using Social Media Optimization (SMO). This research, therefore, attempts to implement SMO on the websites of Batik companies in Madura using Twitter to increase the traffic. In this research, the implementation of SMO on the websites is tested and measured for its significance in improving visitors' traffic. Based on the evaluation, it is found that the implementation of SMO significantly increase the number of visitors' traffic on the website in the second month. Using a paired t-test method, where the correlation before and after SMO implementation on the web is $2 \%$, where $t$ is counted as $3.548>$ t table 1.697 with a grade of significance $0.001<$ alfa 0.05. These findings indicated that the implementation of SMO on the batik company website using Twitter contributed significantly to the increasing of visitors' traffic.
\end{abstract}

Keywords: Social Media Optimization, Twitter, Website, Batik Madura. 


\section{PENDAHULUAN}

Dewasa ini banyak perusahaan telah menggunakan media internet sebagai saluran utama dalam memasarkan produk mereka. Kegiatan pemasaran ini telah lama dikenal sejak dikenalkannya internet dan sering disebut sebagai internet marketing [1]. Salah satu tujuan pemanfaatan internet marketing yaitu untuk meningkatkan kemampuan perusahaan dalam memperluas atau bahkan membuka pasar baru. Hal ini tidak lepas dari kemampuan internet dalam mendiseminasi informasi kepada penggunanya secara interaktif tanpa dibatasi oleh jarak dan waktu.

Dari sekian banyak layanan media persebaran informasi yang disedikan di internet, media sosial adalah salah satu yang paling populer. Kshetr menyebutkan bahwa media sosial memberi pengusaha peluang untuk berkomunikasi dengan pelanggan secara langsung yang merupakan fungsi strategis tambahan yang tidak dapat disediakan oleh search engine dan display network [2]. Dilansir dari data statistik melaporkan bahwa jumlah pengguna internet di dunia mencapai 3,77 miliar, sementara 2,80 miliar merupakan pengguna media sosial [3]. Melihat potensi ini maka layaklah dikatakan bahawa media sosial telah menawarkan perubahan diseminasi yang efisien di berbagai aspek kehidupan termasuk bidang pemasaran.

Namun demikian, di Indonesia terutama para pelaku Industri Kecil Menengah (IKM) pada umumnya hanya mengandalkan website di dalam mendukung pemasaran mereka melalui media internet. Khususnya di Pulau Madura yang terkenal dengan sentra IKM produsen batik dan mempunyai potensi pembeli dari luar pulau atau bahkan luar negeri, para pengusaha masih belum memanfaatkan media sosial dalam website mereka untuk meningkatkan jumlah kunjungan dan menjangkau lebih banyak calon pembeli. Akibatnya website yang dibangun untuk tujuan pemasaran kurang efektif dalam menjangkau pangsa pasar yang lebih luas. Lebih lanjut tidak jarang meskipun sudah memiliki website untuk pemasaran, namun para pengusaha batik di Madura sering kesulitan mendapatkan calon pembeli yang pada akhirnya akan menurunkan pendapatan perusahaan.

Oleh karena itu, dibutuhkan teknik-teknik optimalisasi situs web pemasaran agar dapat menarik calon pembeli potensial untuk berkunjung dan mengakses informasi produk. Setelah itu calon pembeli diharapakan dapat berbagi tautan kepada pengguna internet yang lain. Hal ini dikarenakan semakin banyak jumlah pengunjung dan tautan yang dibagikan dari pengguna jejaring sosial dapat mempengaruhi peringkat konten pada halaman mesin pencari dan memudahkan orang lain untuk menemukannya.

Review terhadap literatur menunjukkan ada berbagai mancam strategi yang dapat diambil. Salah satu cara konvensional menurut Fichter yaitu situs web untuk marketing hendaknya tidak hanya ditempatkan atau diindeks dalam mesin pencari, tetapi juga perlu melakukan analisis jumlah pengunjung dan seberapa baik dukungan serta keterlibatan dengan calon konsumen [4]. Beberapa peneliti juga menyarankan Search Engine Optimization (SEO) sebagai salah satu strategi untuk meningkatkan trafik pengunjung web [5-7].

Cara lain untuk meningkatkan jumlah pengunjung yaitu dengan mengoptimalkan penggunaan media sosial di dalam website atau lebih dikenal dengan istilah Social Media Optimization (SMO). Di dalam literatur tidak ditemukan defisini secara formal tentang SMO. Namun penelitian ini mengadopsi konsep dari Sahai-Goel yang mendefinisikan SMO sebagai salah satu teknik internet marketing dengan memanfaatkan media sosial sebagai saran untuk meningkatkan trafik sebuah website atau menumbuhkan kesadaran akan sebuah produk, media promosi, atau suatu kegiatan kepada konsumen secara luas dan efisien [8].

Penggunaan SMO sebagai salah satu teknik untuk meningkatkan trafik kunjungan web seiring dengan semakin populernya sosial media di kalangan pengguan internet terutama pembeli online. Hal ini sesuai dengan saran dari para ahli di bidang digital marketing, bahwa teknik SMO sangat efektif membantu meningkatkan popularitas serta branding suatu produk [8-10]. Hal yang sama juga dinyatakan dalam penelitian yang dilakukan oleh Rossmann dan Young bahwa hasil penerapan SMO yang telah dilakukan menunjukkan adanya peningkatan terhadap lalu lintas web dan media sosial ke halaman website [11]. Dengan menerapkan lima prinsip SMO untuk meningkatkan sharing informasi dan keterlibatan pengguna. Sedangkan hasil penelitian yang dilakukan oleh Belmonte Jiménez mengemukakan bahwa perusahaan yang tidak mengimplementasi SMO terhadap website-nya menjadikan implantasi perusahaan rendah [12].

Literatur juga memberikan informasi tentang beberapa teknik SMO yang dapat digunakan seperti link, mashup, broadcast, dan web feed $[10,11,13]$. Di samping itu dengan tersedianya berbagai platform di internet, para peneliti juga mengamati seberapa optimal penggunaan berbagai tipe sosial media seperti Twitter, Facebook, dan Instagram dalam menunjang internet marketing. Sebagai contoh menurut Veb dkk. menyimpulkan bahwa penggunaan Twitter dalam web marketing memungkinkan pengunjung memberikan respon secara cepat, sehingga ini dapat membantu meningkatkan trafik kunjungan [14]. Hal yang sama juga diungkapkan dalam penelitian yang dilakukan oleh Crymble, bahwa Twitter menjadi pilihan yang tepat untuk menjangkau audiens yang luas dan mendatangkan trafik ke web [15]. Meskipun Twitter memiliki pengguna yang jauh lebih kecil daripada Facebook, namun perlu diingat bahwa halaman Facebook sebagian besar tidak terlihat oleh pengguna nonFacebook dan dapat menduplikasi konten di situs web utama. Tingkat erosi yang tinggi di antara pengguna Facebook, mencerminkan keraguan tentang upaya yang diperlukan untuk mempertahankan halaman.

Sementara itu penelitian yang dilakukan oleh Sahai-Goel di India menunjukkan hasil yang berbeda yaitu penggunaan Facebook sebagai strategi SMO dalam web perusahaan lebih baik dibandingkan dengan media sosial yang lain termasuk Twitter [8]. Kesimpulan ini tidak mengejutkan karena di India pengguna Facebook jauh lebih besar dibanding media sosial yang lain termasuk Twitter. Hasil yang berbeda juga 
ditunjukkan oleh Buinac dan Lundberg yang menemukan bahwa Instagram adalah media sosial yang paling ampuh untuk optimalisasi website perusahaan, terutama untuk membantu mengkomunikasikan brand image produk mereka secara efisien [16].

Analisis terhadap literatur di atas menunjukkan bahwa studi tentang penggunaan media sosial sebagai teknik SMO telah banyak dilakukan di berbagai negara. Sementara itu belum ada penelitian yang dilakukan dengan mengambil studi kasus IKM pengrajin batik yang berada di Pulau Madura. Hal ini mengingat Pulau Madura sebagai salah satu sentra penghasil batik di Indonesia. Namun demikian banyak diantara mereka yang merugi atau bahkan menutup usaha mereka dikarenakan kesulitan dalam pemasarannya [17].

Oleh karena itu penelitian ini mencoba menerapkan metode SMO dengan memanfaatkan media sosial Twitter karena kemampuannya dalam menjangkau audiens yang luas. Hal ini dikarenakan setiap profil dan tweet yang dipasang selalu diindeks oleh mesin pencari, sehingga tetap bisa ditemukan walaupun telah dihapus. Selain itu setiap kali pengguna melakukan pencarian dengan kata kunci yang sesuai dengan profil atau tweet, maka secara otomatis web hasil optimisasi dengan Twitter akan ditampilkan sehingga secara otomatis akan meningkatkan trafik kunjungan. Hal ini berbeda dengan Facebook yang sebagian besar isinya tidak terlihat oleh pengguna non-Facebook. Alasan lain yaitu kemampuan Twitter melipatgandakan penyiaran sebuah konten melalui fitur retweet, following, dan followers. Hal ini sangat cocok untuk pengoptimalan situs web dengan cara mendorong pengunjung berbagi tautan di jejaring sosial media.

\section{METODOLOGI PENELITIAN}

\section{A. Rancangan Sistem}

Untuk dapat menerapkan teknik SMO pada web pemasaran dengan memanfaatkan media Twitter sesuai tujuan di atas, maka penelitian ini dirancang dengan mengadopsi konsep sistem informasi yang terdiri dari tiga blok yaitu Input, Proses, dan Output. Gambar 1 mengilustrasikan bagaimana rancangan teknik SMO pada web pemasaran diterapkan.

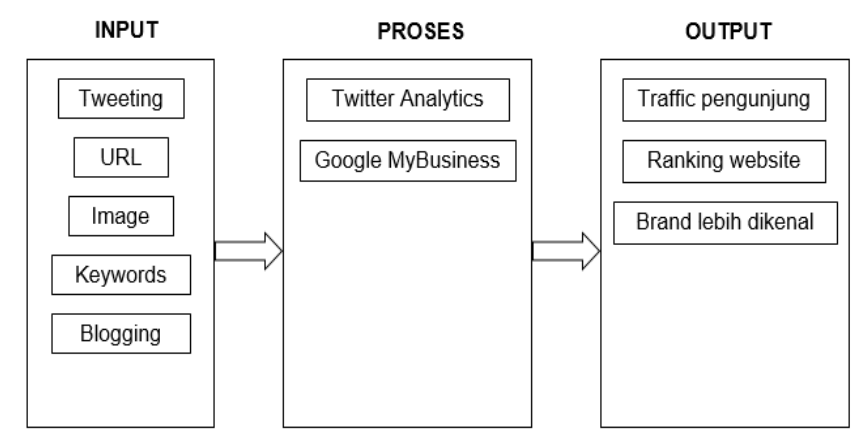

Gambar 1. Gambaran Sistem
Keterangan:

$\underline{\text { INPUT }}$

Indikator yang menjadi inputan dalam proses rancangan ini, yaitu tweeting (meliputi tweet, impressions, retweet, likes, reply, follower), url, image, keywords, dan blogging. Pada tahap ini akan dibuat web penjualan dan akun Twitter. Proses ini direncakan berlangsung selama 4 bulan yaitu dari bulan Agustus-November 2018.

\section{$\underline{\text { PROSES }}$}

Tahap ini dilakukan setelah proses pembuatan web dan akun Twitter selesai, direncankan dari Desember 2018 hingga Februari 2019 dengan rincian sebagai berikut:

1. Pada 1 bulan pertama (Desember 2018) web yang sudah online diamati jumlah kunjungan harian dan dicatat dengan bantuan Google MyBusiness.

2. Selanjutnya pada 2 bulan berikutnya (Januari-Februari 2019) akan dilakukan teknik SMO dengan posting tweet di Twitter yang berisi konten yang relevan, dan akan dilakukan selama 2 atau 3 kali dalam seminggu. Lalu tweet akan dipantau menggunakan Twitter Analytics untuk menganalisis respon dari pengunjung. Twitter Analytics dapat diakses dengan cara mengklik foto profil di kanan atas halaman Twitter lalu pilih menu Analytics. Kemudian user dapat memantau data dari informasi Analytics tersebut terhadap keterlibatan dan penjangkauan audiens. Dari data tersebut, user juga dapat mengekspornya dan memilah tweet yang memperoleh keterlibatan terbaik, sehingga user dapat memanfaatkan strategi konten untuk menjangkau target audiens lebih luas lagi. Kemudian, website juga akan dipantau menggunakan Google MyBusiness. Google MyBusiness dapat diaktifkan dengan cara mendaftar terebih dahulu, kemudian mengisi data tentang informasi bisnis dan memverifikasi data agar dapat memiliki akun. Setelah proses verifikasi selesai, user dapat melihat halaman web dan memberitahu semua informasi tentang trafik yang diterima pada halaman tersebut serta dapat berinteraksi dengan pelanggan.

Setelah data berhasil dikumpulkan maka langkah berikutnya adalah menerapkan SMO pada web pemasaran batik. Ada tiga hal yang akan dilakukan dalam penelitian ini, yaitu:

1. Teknik-teknik SMO yang meliputi links, discussion, description content, update status, retweet, image, broadcast, hashtag, bookmark social, tags, posting blog, title, dan keyword.

2. Website pesona-batik-madura.business.site sebagai uji coba penerapan SMO dalam perkembangan data trafik web, dikarenakan popularitas website melalui media sosial yang masih kurang optimal sehingga perlu dilakukan optimasi.

3. Pengukuran sampel paired t-test mengambil data pengunjung dari Google MyBussiness, dimana untuk menguji ada tidaknya perbedaan dalam proses optimasi sebelum dan sesudah. 


\section{OUTPUT}

Tujuan dari rancangan output ini adalah untuk menghasilkan laporan yang menunjukkan peningkatan kinerja atau popularitas web setelah dilakukan teknik SMO dengan memanfaatkan media Twitter. Ada tiga laporan utama yang akan dihasilkan sebagai bukti bahwa penerapan SMO telah sesuai dan mendapatkan hasil yang optimal. Ketiga laporan itu antara lain:

1. Meningkatkan trafik pengunjung dari media sosial.

2. Meningkatkan ranking website.

3. Brand akan lebih mudah dikenal.

\section{B. Uji Akurasi Paired T-Test}

Adapun langkah-langkah perhitungan uji statistik paired t-test untuk membandingkan data trafik pengunjung sebelum (pre-test) dan setelah (post-test) implementasi SMO, sebagai berikut:

1. Menentukan hipotesis yang digunakan, sebagai berikut:

$$
\begin{array}{ll}
\mathrm{H}_{0}: \mu_{1}=\mu_{2} & \text { (Tidak terdapat perbedaan antara } \\
\mathrm{H}_{1}: \mu_{1} \neq \mu_{2} & \text { pre-test } \text { dan } \text { post-test) } \\
& \text { (Terdapat perbedaan antara pre- } \\
& \text { test dan } \text { post-test) }
\end{array}
$$

2. Hitung nilai rata-rata sampel (mean)

3. Hitung standar deviasi (Sd) untuk mengetahui seberapa besar perbedaan nilai sampel terhadap nilai rata-rata.

4. Menentukan tingkat signifikansi, yaitu alfa 5\% atau 0,05 . Besarnya toleransi dalam mengambil keputusan kesalahan untuk hasil hipotesis terhadap nilai parameter populasi (ukuran standar yang sering digunakan dalam penelitian).

5. Hitung standar error (Se), sebagai alat ukur kesalahan sampling yang digunakan.

6. Hitung $t$, untuk mengetahui kualitas keberartian regresi antara variabel bebas terdapat pengaruh atau tidak terhadap variabel terikat.

7. Tentukan titik tabel distribusi atau $\mathrm{t}$ tabel, untuk mengukur tingkat signifikansi sebuah analisis. Dengan df = banyaknya data $(\mathrm{n})$ - banyaknya variabel $(\mathrm{k})$

8. Menentukan kriteria pengujian, dimana $\mathrm{H}_{0}$ ditolak jika $\mathrm{t}$ hitung $>\mathrm{t}$ tabel dan nilai sig $<0,05$

$\mathrm{H}_{0}$ diterima jika $\mathrm{t}$ hitung $<\mathrm{t}$ tabel dan nilai sig $>0,05$

9. Membuat kesimpulan

Catatan: Jika hasil ada perbedaan, maka dapat dilihat ratarata mana yang lebih tinggi, dengan melihat nilai mean pada paired samples statistic, atau pada t hitung. Jika t hitung positif berarti rata-rata pre-test lebih tinggi daripada post-test dan sebaliknya thitung negatif berarti rata-rata pre-test lebih rendah daripada post-test.

\section{HASIL DAN PEMBAHASAN}

Pada bagian ini akan dibahas hasil dari penelitian berdasarkan metodologi yang telah dipaparkan sebelumya.
Pada tahap ini dilakukan pembuatan akun di media sosial Twitter. Pada penelitian ini akun yang dibuat sesuai dengan nama web sebagai studi kasus, Pesona Batik Madura (PBM), yaitu@GaleriPbm. Setelah akun berhasil dibuat maka dilakukan pengaturan yang terdiri dari deskripsi singkat, foto, dan nama tampilan.

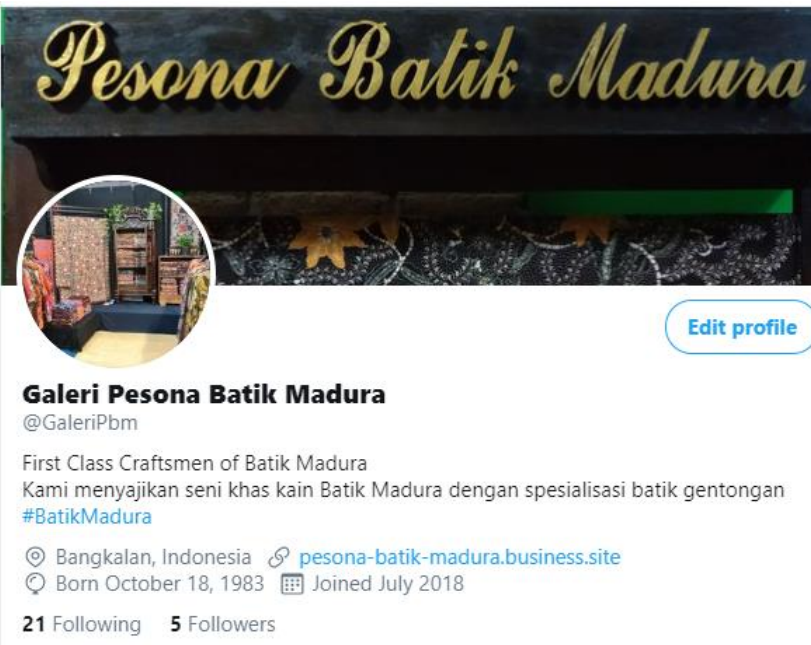

Gambar 2. Screenshot Profil Twitter@GaleriPbm

Pengaturan yang lain yaitu informasi berkaitan dengan profil usaha Pesona Batik Mudara seperti alamat, lokasi di peta dan tanggal mulai usaha. Salah satu bagian yang terpenting pada tahap pengaturan ini yaitu menghubungkan (link) akun Twitter dengan website Pesona Batik Madura yang akan dilakukan optimasi. Gambar 2 menunjukkan hasil dari proses pengaturan akun di Twitter sehingga siap dimanfaatkan dalam SMO.

Setelah seluruh proses pengaturan dan link dengan web siap, selanjutnya dibuat posting tweet untuk mempromosikan website penjualan batik Madura. Pada setiap posting juga disertakan hastag atau tanda pagar (\#) yang disesuaikan dengan tema pemasaran yang sedang di-posting. Penggunaan hashtag harus menggunakan frasa yang menarik. Salah satu tujuan utamanya adalah agar menarik pengunjung untuk membagikan postingan tersebut kepada orang lain melalui posting di akun media sosial mereka atau media komunikasi yang lain.

Penggunaan frasa hashtag yang menarik ini akan memberikan manfaat bagi peningkatan popularitas akun Twitter@GaleriPbm dan juga web PBM media sosial. Hal ini dikarenakan setiap pengunjung membagikan lagi hashtag tersebut dalam posting mereka kemudian pada saat yang sama banyak pengguna juga menggunakannya. Secara tidak langsung telah menjadikan hastag tersebut menjadi trending topic. Sebagai dampak positifnya yaitu akun Twitter dan juga web PBM akan meningkat popularitasnya. Gambar 3 di bawah ini menunjukkan salah satu contoh posting promosi disertai dengan hastag yang menarik di akun Twitter yang sudah dihubungkan dengan web PBM

\section{A. Implementasi}



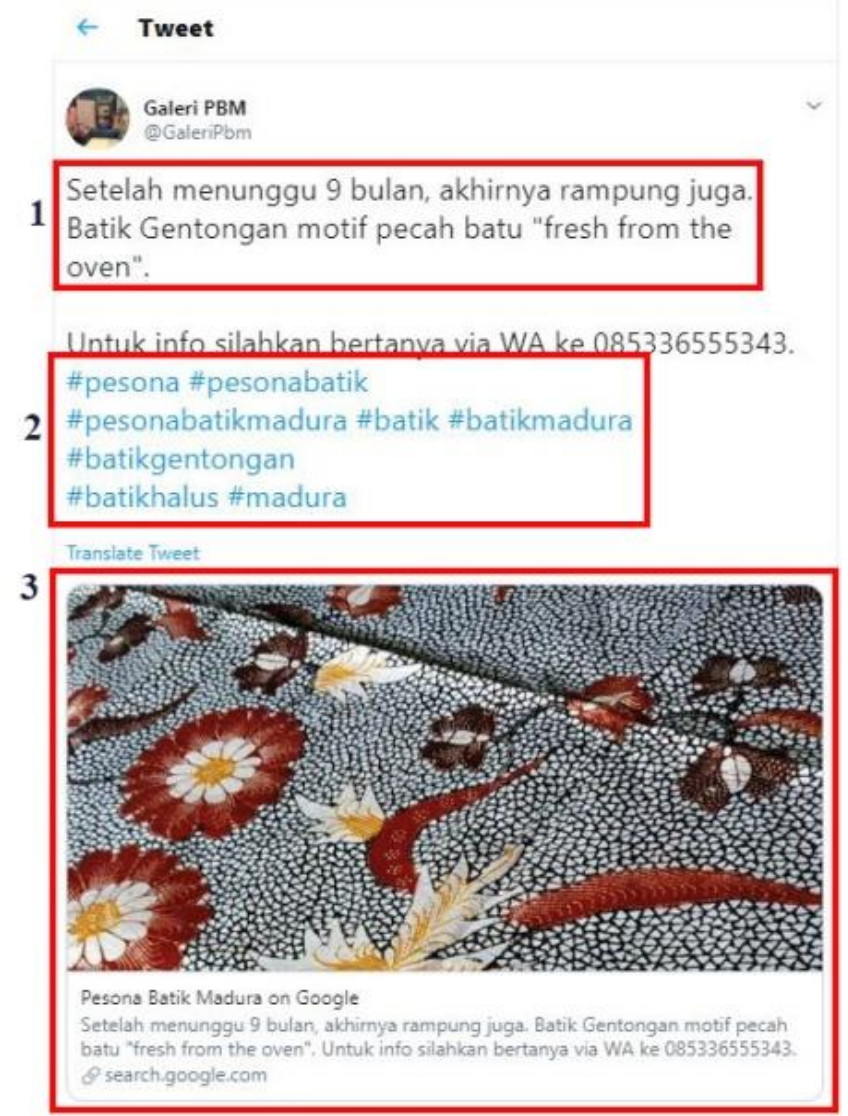

11:24 AM - Feb 2, 2019 - Twitter for Android

41 Retweets 1 Like

Gambar 3. Screenshot Contoh Tampilan Tweet

Pada Gambar 3 juga dapat kita temukan beberapa informasi penting pada posting tweet di Twitter, antara lain:

1. Deskripsi konten dan keyword - adapun keyword dari tweet ini adalah "Batik Gentongan" dan pemberian deskripsi untuk menjelaskan konten terkait.

2. Hashtag - terdapat beberapa hashtag yang digunakan dalam tweet ini, seperti \#batikmadura, \#batikgentongan, dan lain-lain untuk memudahkan pencarian audiens.

3. Link dan Image - tambahan link untuk mengarahkan pengguna mengunjungi web serta image untuk menarik pengguna dalam postingan tweet sesuai konten.

4. Engagment - tweet dari Gambar 3 mendapat likes 1 kali dan 1 retweet dari pengguna. Untuk keseluruhan hasil engagement dari tweet dapat dilihat pada Gambar 4.

Gambar 4 merupakan tampilan hasil tweet analytics dari salah satu tweet. Jumlah impresi yang didapatkan dari tweet ini adalah 474, yang artinya sebanyak 474 orang yang melihat tweet tersebut. Sedangkan total engagment yang didapat adalah 4, yang berarti 2 kali pengguna mengklik link tersebut untuk mengunjungi website, pengguna yang meretweet hanya 1 yang berarti tweet ini hanya dibagikan 1 kali oleh pengguna lain untuk disebarkan ke followers mereka, dan pengguna yang menyukai tweet ini hanya 1 .

\author{
Galeri PBM@GaleriPbm \\ Setelah menunggu 9 bulan, akhirnya rampung \\ juga. Batik Gentongan motif pecah batu "fresh \\ from the oven". \\ Untuk info silahkan bertanya via WA ke \\ 085336555343 . \\ \#pesona \#pesonabatik \\ \#pesonabatikmadura \#batik \#batikmadura \\ \#patikgentongan \\ \#batikhalus \#madura \\ https://goo.gl/posts/htxx4
}

Impressions

474

times people saw this Tweet on Twitter

Total engagements

times people interacted with this Tweet

clicks on a URL or Card in this Tweet

Retweets

times people retweeted this Tweet

Likes

times people liked this Tweet

Gambar 4. Tampilan Interaksi Tweet Analytics

Selain di media sosial Twitter, posting blog juga dilakukan dan beberapa teknik optimasi yang diterapkan terhadap website pesona batik Madura. Dikarenakan posting yang up to date dan relevan dapat membantu menarik pengunjung untuk mengunjungi website guna mengetahui informasi lebih jauh.
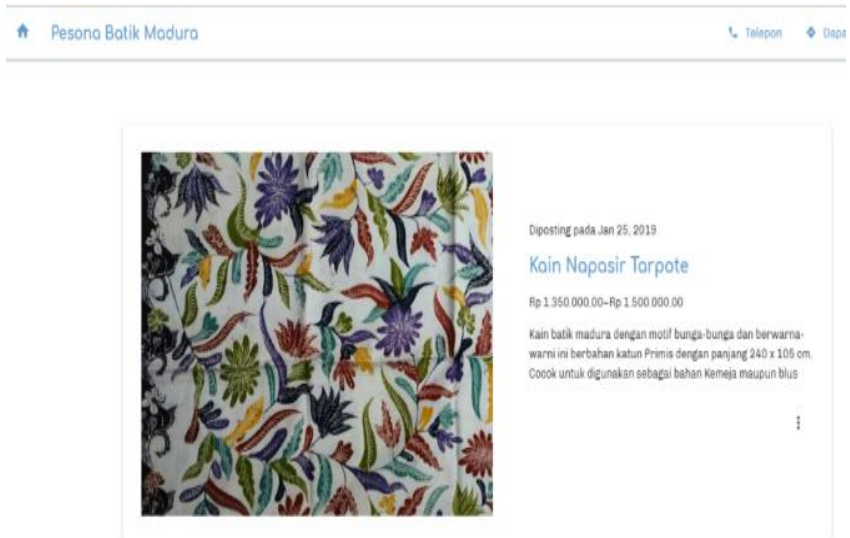

Gambar 5. Screenshot Posting Blog

Gambar 5 merupakan posting di web. Pada posting tersebut terdapat beberapa teknik yang meliputi hashtag untuk memudahkan pengguna menemukan konten, description content untuk memberikan konten yang relevan, image yang dapat menarik pengunjung, title untuk memberi kemudahan pengunjung dan mesin pencari mengenai topik yang dicari, serta menambahkan harga penjualan untuk menentukan pembelian. 
Pada Gambar 6 merupakan komentar-komentar pengunjung dan vote terhadap produk batik Madura. Dengan adanya respon yang diberikan pelanggan tersebut, dapat membantu menambah rating pencarian dan tetap menjaga kepercayaan pelanggan terhadap produk batik ini, baik pelanggan lama maupun baru.

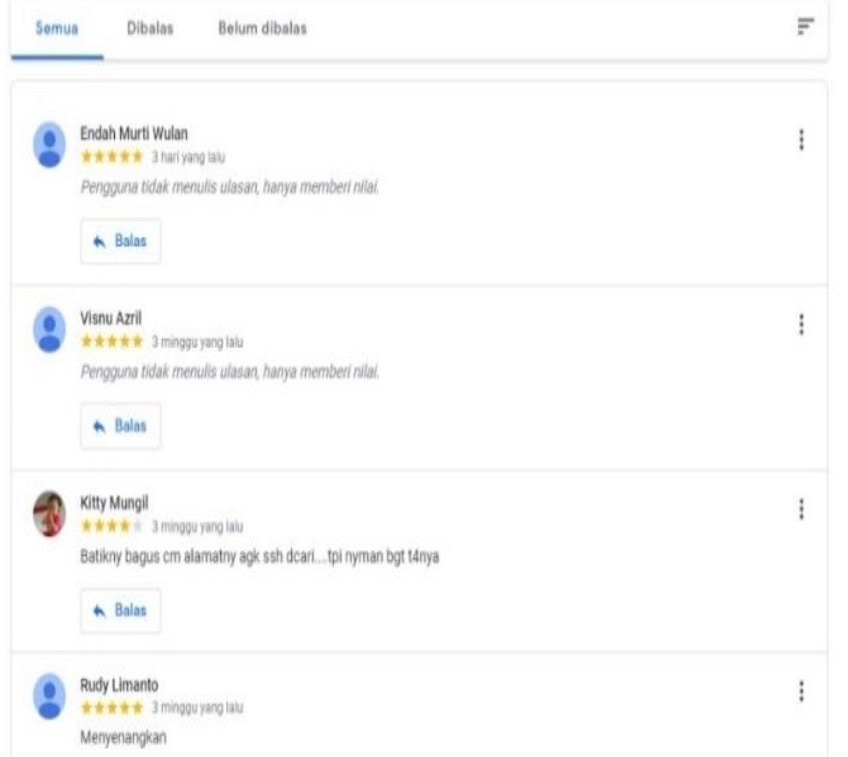

Gambar 6. Screenshot Diskusi Pelanggan

<meta name='keywords' content=' Pesona Batik Madura, Batik, Batik Madura, Batik Tulis Madura, Batik Bangkalan, Batik Gentongan, Kain Batik'>

Kode di atas merupakan keyword pilihan yang diletakkan pada meta keyword halaman website. Adapun keyword tersebut bisa membantu agar website tersebut mudah ditemukan ketika keyword dicari pada mesin pencari.

<title>Pesona Batik Madura - Toko Pakaian</title>

$<$ meta name='description' content='Pesona Batik Madura Kami menyajikan sebuah seni khas batik Madura dengan spesialisasi batik gentongan, sebuah teknik membatik dan pewarnaan menggunakan gentong yang telah berumur ratusan tahun'>

Kode program untuk title tag dan meta description dibuat untuk mempermudah search engine mengenali website. Title tag mendeskripsikan judul halaman website agar mempengaruhi hasil pencarian search engine. Sementara, meta description mendeskripsikan rangkuman dan inti topik pembahasan di dalam website agar menarik perhatian pengunjung untuk mengakses website.

Perkembangan pengunjung dapat dilihat di tools Google MyBussiness, dengan mengklik insight seperti terlihat pada Gambar 7 berikut ini. Gambar 7 merupakan data trafik yang dihasilkan pengunjung, baik dari media sosial Twitter maupun dari website sehingga dari data tersebut, peneliti mengakumulasi data untuk mengukur perbandingan pengunjung sebelum dan sesudah proses optimasi media sosial menggunakan twitter.

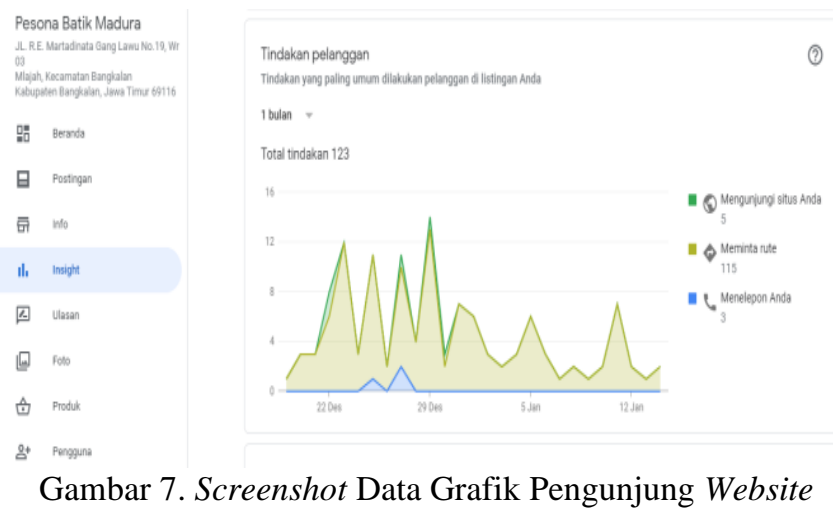

\section{B. Hasil Uji Akurasi}

Pengujian ini dilakukan untuk mengetahui seberapa besar pengaruh metode SMO yang telah diimplementasikan. Masa pengujian dilakukan selama 3 bulan dimulai pada bulan Desember 2018 hingga Februari 2019. Pengujian yang dilakukan terbagi menjadi 2 sesi seperti yang dijelaskan berikut ini:

\section{Pengujian 1 - Tanpa SMO}

Pengujian tahap 1 ini dimulai pada tanggal 1 hingga 31 Desember. Pada tahap ini website tidak dilakukan penerapan teknik SMO. Berikut akan ditampilkan hasil dari pengujian tahap 1 dengan melihat rank pencarian dan jumlah pegunjung yang diperoleh dari statistik Google MyBussiness setelah dioptimasi pada bulan 1-31 Desember dan hasil nilai akurasinya terlihat pada Tabel 1 berikut ini.

Tabel 1. Data Sampel Tahap I

\begin{tabular}{|r|rr}
\hline SAMPLE & \multicolumn{1}{|c}{ PRE-TEST } & POST-TEST \\
\hline $\mathbf{1}$ & 3 & 1 \\
\hline $\mathbf{2}$ & 4 & 4 \\
\hline $\mathbf{4}$ & 5 & 1 \\
\hline $\mathbf{5}$ & 8 & 4 \\
\hline $\mathbf{6}$ & 1 & 2 \\
\hline $\mathbf{7}$ & 2 & 1 \\
\hline $\mathbf{8}$ & 8 & 4 \\
\hline $\mathbf{9}$ & 2 & 6 \\
\hline $\mathbf{1 0}$ & 1 & 3 \\
\hline $\mathbf{1 1}$ & 1 & 3 \\
\hline $\mathbf{1 2}$ & 0 & 8 \\
\hline $\mathbf{1 3}$ & 3 & 3 \\
\hline $\mathbf{1 4}$ & 1 & 3 \\
\hline $\mathbf{1 5}$ & 2 & 9 \\
\hline $\mathbf{1 6}$ & 1 & 4 \\
\hline $\mathbf{1 7}$ & 1 & 7 \\
\hline $\mathbf{1 8}$ & 2 & 3 \\
\hline $\mathbf{1 9}$ & 1 & 3 \\
\hline $\mathbf{2 0}$ & 8 & 0 \\
\hline & 1 & 2 \\
\hline
\end{tabular}




\begin{tabular}{|r|rr}
\hline $\mathbf{2 1}$ & 0 & 5 \\
\hline $\mathbf{2 2}$ & 1 & 4 \\
\hline $\mathbf{2 3}$ & 6 & 10 \\
\hline $\mathbf{2 4}$ & 3 & 2 \\
\hline $\mathbf{2 5}$ & 0 & 16 \\
\hline $\mathbf{2 6}$ & 5 & 8 \\
\hline $\mathbf{2 7}$ & 7 & 6 \\
\hline $\mathbf{2 8}$ & 5 & 5 \\
\hline $\mathbf{2 9}$ & 5 & 11 \\
\hline $\mathbf{3 0}$ & 5 & 9 \\
\hline $\mathbf{3 1}$ & 0 & 3 \\
\hline
\end{tabular}

Berdasarkan data pengunjung website terlihat di hari pertama memiliki 3 orang pengunjung, kemudian mengalami kenaikan tertinggi hingga 8 orang pengunjung. Lalu pengunjung mengalami fluktuasi sampai di minggu-minggu terakhir. Berdasarkan pengujian tahap 1 ini dapat ditarik kesimpulan bahwa website yang tidak diterapkan teknik SMO bisa terdeteksi oleh mesin pencari Google namun butuh berhari-hari untuk dapat menaikkan rating website dan jumlah pengunjung. Hal ini dapat diartikan bahwa kurangnya penerapan metode SMO pada website akan kalah bersaing dengan website lainnya. Berdasarkan data ini pula dilakukan ujicoba akurasi Paired T-Test seperti ditujukkan tabel 2.

Tabel 2. Tabel Hasil Uji Coba Akurasi Tahap I

\begin{tabular}{|lcc}
\hline & Pre-Test & Post-Test \\
\hline Means & 2,9677419 & 4,83870967 \\
\hline Standar deviasi & 2,562341 & 3,5128030 \\
\hline n & 31 \\
\hline Korelasi & $-0,022817061$ \\
\hline df & 30 \\
\hline Rata-rata Sd & 4,395011835 \\
\hline Standar error & 0,789367428 \\
\hline T hitung & 2,370211482 \\
\hline p-value & 0,02440444 \\
\hline
\end{tabular}

Tabel 2 menunjukkan hasil uji statistik nilai $\mathrm{t}$ bulan pertama menunjukkan bahwa t hitung adalah 2,370 dengan sig 0,024. Karena signifikansi yang digunakan adalah 0,05 , maka sig 0,024 > $\alpha 0,05$, maka $\mathrm{H}_{0}$ diterima dan $\mathrm{H}_{1}$ ditolak, yang artinya bahwa pengunjung website antara sebelum dioptimasi dengan setelah dioptimasi SMO belum ada perbedaan yang signifikan atau dapat disimpulkan bahwa proses metode SMO belum mempengaruhi jumlah pengunjung.

\section{Pengujian 2 - Dengan SMO}

Pada proses ini seluruh proses SMO akan dilakukan setelah melewati masa pengujian 1. Berikut akan ditampilkan hasil dari pengujian tahap 2 dengan melihat rank pencarian dan pengunjung website ang di peroleh dari statistik Google MyBussiness.
Tabel 3. Data Sampel Tahap II

\begin{tabular}{|c|c|c|}
\hline SAMPLE & PRE-TEST & POST-TEST \\
\hline 1 & 3 & 2 \\
\hline 2 & 4 & 7 \\
\hline 3 & 5 & 10 \\
\hline 4 & 8 & 5 \\
\hline 5 & 1 & 3 \\
\hline 6 & 2 & 2 \\
\hline 7 & 8 & 9 \\
\hline 8 & 2 & 1 \\
\hline 9 & 1 & 18 \\
\hline 10 & 1 & 12 \\
\hline 11 & 0 & 1 \\
\hline 12 & 3 & 8 \\
\hline 13 & 1 & 1 \\
\hline 14 & 2 & 5 \\
\hline 15 & 1 & 4 \\
\hline 16 & 1 & 2 \\
\hline 17 & 2 & 6 \\
\hline 18 & 1 & 6 \\
\hline 19 & 8 & 9 \\
\hline 20 & 1 & 6 \\
\hline 21 & 0 & 3 \\
\hline 22 & 1 & 9 \\
\hline 23 & 6 & 3 \\
\hline 24 & 3 & 3 \\
\hline 25 & 0 & 5 \\
\hline 26 & 5 & 8 \\
\hline 27 & 7 & 9 \\
\hline 28 & 5 & 2 \\
\hline 29 & 5 & 3 \\
\hline 30 & 5 & 6 \\
\hline 31 & 0 & 8 \\
\hline
\end{tabular}

Berdasarkan hasil analisis yang diperoleh dari statistik Google MyBussiness selama bulan Januari. Pengunjung website pada minggu pertama mengalami fluktuasi namun pengunjung semakin bertambah, sampai pada hari ke 25 mengalami kenaikan hingga 16 pengunjung. Kemudian web mengalami fluktuasi kembali selama beberapa hari ke depan. Kesimpulan yang dapat ditarik dari pengujian ini adalah adanya peningkatan rank pada pencarian dan pengunjung website setelah dilakukannya penerapan SMO. Walaupun ranking di pencarian tidak menempati posisi awal, namun ranking sudah mengalami kenaikan meskipun terjadi fluktuasi. Berdasarkan data ini pula dilakukan uji coba akurasi Paired T-Test seperti ditujukkan Tabel 4.

Tabel 4. Hasil Perhitungan Post-Test Bulan Kedua

\begin{tabular}{lcc} 
& Pre-Test & Post-Test \\
\hline Means & 2,9677419 & 5,6774193 \\
\hline Standar deviasi & 2,562341 & 3,798131 \\
\hline n & \multicolumn{2}{c}{31} \\
\hline Korelasi & 0,149599017 \\
\hline df & \multicolumn{2}{c}{30} \\
\hline Rata-rata Sd & 4,252007748 \\
\hline
\end{tabular}




\begin{tabular}{cc}
\hline Standar error & 0,763683136 \\
\hline T hitung & 3,548169774 \\
\hline p-value & 0,001299173 \\
\hline
\end{tabular}

Tabel 4 menunjukkan hasil uji statistik nilai $\mathrm{t}$ bulan kedua menunjukkan bahwa thitung adalah 3,548 dengan sig 0,001. Karena signifikansi yang digunakan adalah 0,05, maka sig $0,001<\alpha 0,05$ dan thitung 3,548 $>\mathrm{t}$ tabel 1,697, maka $\mathrm{H}_{0}$ ditolak dan $\mathrm{H}_{1}$ diterima, yang artinya bahwa pengunjung website antara sebelum dioptimasi dengan setelah dioptimasi SMO ada perbedaan yang signifikan. Atau dapat disimpulkan bahwa proses metode SMO mempengaruhi jumlah pengunjung.

\section{KESIMPULAN}

Dari data hasil pengujian implementasi metode SMO terhadap website penjualan online batik Madura sebagai promosi internet menunjukkan adanya peningkatan pengunjung website. Dilihat dari hasil pengujian dengan nilai signifikansi yang digunakan adalah 0,05 untuk hasil keputusan dari nilai probabilitas di bulan pertama, tidak mengalami perubahan karena $\mathrm{t}$ hitung 2,37 dengan nilai signifikansi 0,024 (atau > alfa 0,05). Namun pada bulan kedua nilai t hitung 3,548 dengan nilai signifikansi 0,001, yang berarti < alfa 0,05 dan hipotesis diterima. Dengan demikian dapat disimpulkan bahwa proses metode SMO mempengaruhi jumlah pengunjung, walaupun peningkatan yang diperoleh baru terjadi di bulan kedua dan masih sering mengalami fluktuasi. Potensial Twitter yang tidak seperti media sosial Facebook dimana memiliki lebih banyak pengguna, sehingga kurang memberikan respon yang signifikan.

\section{V.SARAN DAN REKOMENDASI}

Setelah melakukan penelitian dan uji coba penerapan metode SMO pada web penjualan Batik dengan memanfaatkan media Twttter, ada beberapa saran yang dapat diterapkan oleh pengusaha batik sebagai pengguna dan rekomendasi penelitian di masa mendatang untuk perbaikan agar didapat hasil yang lebih optimal, antara lain:

1) Dari hasil uji coba menunjukkan tingkat kunjungan akan cenderung meningkat ketika tema tweet dan konten web berisi hal yang menjadi daya tarik dan disukai pengunjung atau calon pembeli batik, misalnya \#cashback, \#clearence, \#diskon dan \#new_arrival. Oleh karena itu sangat penting bagi pengusaha batik yang memanfaatkan Twitter sebagai SMO agar membuat konten atau hastag yang menarik untuk menciptakan atensi dan interaksi pengunjung yang lebih besar.

1) Dengan kemampuan Twitter dalam melipatgandakan penyebaran sebuah konten melalui fitur retweet, following, dan followers, maka untuk efisiensi disarankan selain melakukan posting, juga aktif melakukan follow atau retweet akun resmi para tokoh masyarakat, selebriti, atau influencer yang memiliki basis pengikut yang banyak, sehingga pesan yang disampaikan juga sampai ke pengikutnya dan berpotensi meningkatkan trafik kunjungan web.

2) Untuk saran perbaikan, penelitian ke depan akan lebih baik jika penggunaan SMO pada website penjualan online batik Madura juga diiringi dengan media sosial lainnya, seperti Facebook, MySpace, dan Instagram yang masing-masing memiliki kelompok pengguna dan fitur yang berbeda.

\section{REFERENSI}

[1] Kiang, M.Y., Santanam, R., \& Shang, K.H.M. (2000). Marketing on the Internet - who can benefit from an online marketing approach? Decision Support Systems, Vol. 27(4), pp. 383-393. DOI: 10.1016/S01679236(99)00062-7

[2] Kshetri, N. (2012). Privacy and Security Aspects of Social Media: Institutional and Technological Environment. The Pacific Asia Journal of the Association for Information Systems, Vol. 3(4), pp. 120. DOI: $10.17705 / 1$ pais.03401

[3] Kemp, S. (2017). Digital in 2017 Global Overview: a Collection of Internet, Social Media, and Mobile Data From Around the World [PowerPoint Slides].

[4] Fichter, D. (2007). How Social is Your Web Site? Top Five Tips for Social Media Optimization. Online, Vol. 31(3), pp. 57-60.

[5] Lukito, R.B., Lukito, C. \& Arifin, D. (2014). Penerapan Teknik SEO (Search Engine Optimization) Pada Website Dalam Strategi Pemasaran Melalui Internet. ComTech: Computer, Mathematics and Engineering Applications. Vol. 5(2), pp. 1050-1058.

[6] Hernawati, K. (2009). Optimalisasi SEO (Search Engine Optimizer) Sebagai Upaya Meningkatkan Unsur Visibility Dalam Webometric. Prosiding Seminar Nasional Matematika dan Pendidikan Matematika 2009.

[7] Achmady, S. \& Irawan, B. (2014). Analysis Teknik Search Engine Optimization pada Website terhadap Search Engine Results Page Google. International Journal of Science, Vol. 10, pp. 15-30.

[8] Sahai, S., Goel, R., Malik, P., Krishnan, C., Singh, G. \& Bajpai, C. (2018). Role of Social Media Optimization in Digital Marketing with Special Reference to Trupay. International Journal of Engineering \& Technology, Vol. 7(2.11), pp. 52-57.

[9] Xiang, Z. \& Gretzel, U. (2010). Role of Social Media in Online Travel Information Search. Tourism Management, Vol. 31(2), pp. 179-188.

[10] Ballings, M., Van den Poel, D. \& Bogaert, M. (2016). Social Media Optimization: Identifying an Optimal Strategy for Increasing Network Size on Facebook. Omega, Vol. 59, pp. 15-25.

[11] Rossmann, D. \& Young, S.W. (2015). Social Media Optimization: Making Library Content Shareable and Engaging. Library Hi Tech, Vol. 33(4), pp. 526-544. 
[12] Jiménez, A.B. (2011). Social Media Optimization. Implementation in SME's Websites of the" Parque Tecnológico de Andalucía" [Disertasi].

[13] Troudi, A., Zayani, C.A., Jamoussi, S. \& Amor, I.A.B. (2018). A New Mashup Based Method for Event Detection from Social Media. Information Systems Frontiers, Vol. 20(5), pp. 981-92.

[14] Rizal, V.Z. \& Lubis, E.E. (2014). Pengaruh Social Media Marketing Twitter Terhadap Terbentuknya Brand Image Restoran Burger Gaboh Pekanbaru. Jurnal Online Mahasiswa Bidang Ilmu Sosial dan Ilmu Politik, Vol. 1(2), pp. 1-15.
[15] Crymble, A. (2010). An Analysis of Twitter and Facebook Use by The Archival Community. The Journal of The Association of Canadian Archivists. pp. 125-151.

[16] Buinac, E.R. \& Lundberg, J. (2015). Instagram as a Marketing Tool: a Case Study About How Companies Communicate Their Brands on Social Media [Thesis].

[17] Hindratmo, A. \& Riyanto, O.A.W. (2019). Enhancing Capability of Tanjung Bumi Batik Sales Bangkalan Madura. Kontribusia (Research Dissemination for Community Development), Vol. 2(1), pp. 4-8. 